\title{
Temel Eğitim Ders Kitaplarında Orhun Yazıtlarının Durumu
}

\author{
DOI: $10.26466 /$ opus.602977
}

Öz

Milletlerin değer yargıları, inançları, gelenek ve görenekleri kısacası hayatı algılama biçimleri olan kültürleri birbirinden farklıdır. Dolayısıyla her milletin eğitimden ve süreç sonundaki çıktı durumundaki öğrenciden beklentileri farklıdır. Bu açıdan eğitimin evrensel nitelikli olması kadar millî ve "kendine özgü" olması da büyük önem taşımaktadır. Teknolojik gelişmelere rağmen hâlen dünyada en yangın kullanılan ders araç gereçlerinin başında ders kitapları gelmektedir. Bu açıdan eğitsel hedeflere ulaşmada üzerine en fazla görev düşen eğitim araçları ders kitaplarıdır. Bu araştırmanın amacı temel eğitim ders kitaplarında Orhun Yaztlarının durumunun tespit edilmesidir. Doküman incelemesi yöntemiyle yürütülen araştırma kapsamında 2018-2019 eğ itim öğretim yılı içerisinde Millı̂ Ĕ̆itim Bakanlığı ve çeşitli yayınevleri tarafindan ilkokul, ortaokul ve lise düzeyinde kullanılmak üzere yayınlanmış Türkçe, Hayat Bilgisi, Sosyal Bilgiler, Tarih, T.C. Inkılap Tarihi ve Atatürkçülük ile Türk Dili ve Edebiyatı ders kitapları Orhun Yazıtları ile ilgili içerik ve görsel açısından değerlendirilmiştir. 24 ders kitabının incelendiğ $i$ araştırmanın sonucunda ilkokul ders kitaplarında Orhun Yazıtlarıla ilgili herhangi bir bilgi ve görsele yer verilmediği ortaokul ve lise düzeyinde ise çok sınırlı bir biçimde yer verildiği tespit edilmiştir.

Anahtar Kelimeler: Temel eğitim, Ders kitabı, Orhun Yazıtları, Doküman inceleme 


\title{
The Place of Orkhon Inscriptions in Basic Education Course Books
}

\begin{abstract}
Cultures of nations, including their value judgments, beliefs, and traditions, all of which make up their perception of life, are different from each other. Therefore each nation has different expectations from education and from students who are the outputs of this process. In this respect, it is very important for education both to have universal qualities and to be national and "specific". In spite of all technological developments, course books are still one of the most commonly used educational tools in the world. Accordingly, the educational tools that play the biggest part in attaining educational goals are course books. This study is aimed at determining the place of Orkhon Inscriptions in basic education course books. Within the scope of the research that was conducted using document review method, course books such as Turkish language, Life Sciences, Social Sciences, History, T.R. History of Revolutions and Kemalism and Turkish Language and Literature published in 2018-2019 academic year by the Ministry of National Education and various publishers to be taught at primary, secondary and high school levels were evaluated with regard to their written and visual content related to Orkhon Inscriptions. At the end of the research that involved a review of 24 coursebooks, it was determined that primary school course books include no information or visuals about Orkhon Inscriptions, while secondary and high school books have a very limited content.
\end{abstract}

Keywords: Basic education, Course book, Orkhon Inscrisptions, Document analysis 


\section{Giriş}

Farklı birçok tanımı bulunmakla birlikte temelde "Tarihsel, toplumsal gelişme süreci içinde yaratılan bütün maddi ve manevi değerler ile bunları yaratmada, sonraki nesillere iletmede kullanılan, insanın doğal ve toplumsal çevresine egemenliğinin ölçüsünü gösteren araçların bütünü" (TDK, 2011, s. 20) biçiminde açılanabilecek kültürün aktarımı; birey ve toplum açısından hayati önem taşır.

Bireyin içinde doğduğu milletin kültürünü öğrenmesi aslında hem hayata karşı kendine (temelde millete) özgü bir bakış açısı kazanmasını hem de "ben" in ötesine geçerek "biz"e ulaşmasını yani milletin parçası olmasını sağlayan bir kimlik kazanma sürecidir (Mora, 2008; Mert, Bay, Alyılmaz ve Akbaba, 2010; Alyılmaz ve Alyılmaz 2014). Bu süreç bireyde öyle derin izler bırakır ki örneğin "Başka bir cemiyetin içinde daha büyük bir refahla yaşamamız mümkün iken, cemiyetimiz içindeki fakirliği ona tercih ederiz. Çünkü dostlar içindeki bu fakirlik, yabancılar arasındaki o refahtan ziyade bizi mutlu kılar" (Gökalp, 2015, s. 37). Dolayısıyla ortak kültürün insanları sevinçte, tasada ve özellikle de ortak bir gelecek arzusunda birleştirdiği söylenebilir.

Kültürün aktarılamaması durumunda nesiller arasındaki biyolojik bağ milletin devamı açısından yeterli değildir (Mert, Alyılmaz, Bay ve Akbaba, 2009). Bu nedenle kültür aktarımı milletler açısından bir varlık yokluk meselesidir (Kolaç, 2010; Er ve Bozkırlı, 2018; Şahin, 2019).

Bireyde kendi yaşantıları yoluyla istendik davranış değişikliği meydana getirme süreci olan eğitimle kazandırılacak "istendik davranış"tan kasit şüphesiz çağın gereklerine uygun bilgiyle donanmak olduğu kadar ferdi olunan millete özgü değerleri kazanmış olmaktır. Yani eğitimle çağdaşlaşma kadar nesiller arasındaki ortak düşünce, inanç ve yaşayış bağlantısını sağlayacak kültür aktarımı da hedeflenmelidir (San, 1988; Kavcar, 1999). Zira tarih, adı bilinen ancak mevcudiyetini kaybetmiş milletlerin örnekleriyle doludur.

Milletlerin değer yargıları, inançları, gelenek ve görenekleri kısacası hayatı algılama biçimleri olan kültürleri birbirinden farklıdır. Dolayısıyla her milletin eğitimden ve süreç sonundaki çıktı durumundaki öğrenciden beklentileri farklıdır. Bu açıdan eğitimin evrensel nitelikli olması kadar millî ve "kendine özgü" olması da büyük önem taşımaktadır. 
Teknolojik gelişmelere rağmen hâlen dünyada en yangın kullanılan ders araç gereçlerinin başında ders kitapları gelmektedir (Yılar, 2016; Doğan ve Torun, 2018). Bu açıdan eğitsel hedeflere ulaşmada üzerine en fazla görev düşen eğitim araçları ders kitaplarıdır. Dolayısıyla ders kitapları eğitimin kültür aktarımı işlevine hizmet edecek nitelikte olmalıdır.

Ders kitapları ülkenin eğitim politikalarının ve öğretim programlarında amaç ve hedeflere dönük idealize edilmiş görüşlerin uygulamadaki karşılıklarıdır (Bayram ve Elban, 2017). Yani ders kitapları eğitimin ülkedeki gerçek durumunu yansitan aynalar olarak değerlendirilebilir. $\mathrm{Bu}$ bağlamda ders kitapları üzerine yapılacak araştırmaların genel olarak eğitim sistemindeki özelde ise derslerin içeriklerindeki ve uygulamalarındaki -varsa- eksikliklerin ve yanlışların tespitine katkı sağlayacağı düşünülmektedir. Bu araştırma ile alana böyle bir katkı sunulmakla birlikte Türk dili, tarihi, edebiyatı, kültürü... açısından büyük önem taşıyan ve uzun bir süre Türklerin ilk yazılı kaynakları olarak kabul edilen Orhun Yazıtlarının (Alyılmaz, 2005; Alyılmaz, 2007) Türk eğitim sisteminin önemli ve uzun bir kısmını oluşturan temel eğitimdeki yerini göstermesi araştırmanın asıl önemli yanıdır.

Yapılan alan yazın taramasında temel eğitim aşamasındaki derslere ait farklı düzeylerden ders kitaplarının içeriklerinin çeşitli açılardan değerlendirildiği araştırmalara (Pehlivan ve Kolaç, 2016; Yılar, 2016; Bayram ve Elban, 2017; Kaşkaya ve Duran, 2017; Arseven, Yolcu ve Kılıç, 2018; Barutçu ve Açı, 2018; Doğan ve Torun, 2018; Ecerkale ve Bayrak, 2018; Ünveren Kapanadze, 2018) rastlanmakla birlikte, temel eğitim ders kitaplar1nın bir arada değerlendirildiği ve Orhun Yazıtlarının bu kitaplardaki durumunun ortaya konulduğu herhangi bir araştırmaya rastlanmamıştır. Araştırmanın temel gerekçesini bu eksiklik oluşturmaktadır.

\section{Yöntem}

Araştırma temel eğitim ders kitaplarının incelenmesine dayalı yürütüldügünden doküman incelemesine dayalı nitel bir araştırmadır. Doküman incelemesi, basılı ve elektronik materyallerin sistematik bir biçimde değerlendirilmesine dayanan bir araştırma yöntemidir (Bowen, 2009) 


\section{İncelenen Dokümanlar}

Araştırma kapsamında 2018-2019 eğitim-öğretim yılı içerisinde ilkokul, ortaokul ve lise düzeyinde okutulan Türkçe, Hayat Bilgisi, Sosyal Bilgiler, Tarih, T.C. İnkılap Tarihi ve Atatürkçülük ile Türk Dili ve Edebiyatı ders kitapları Orhun Yazıtları ile ilgili içerik ve görseller açısından incelenmiştir. İlgili ders kitapları Orhun Yazıtları ile ilgili bilgiler içerdiği varsayıldığından seçilmiştir.

\section{Veri Analizi}

Temel eğitim ders kitapları araştırma kapsamında incelenirken elde edilen verilerin analizinde içerik analizi yöntemi kullanılmıştır. "İçerik analizinde temelde yapılan işlem, birbirine benzeyen verileri belirli kavramlar ve temalar çerçevesinde bir araya getirmek ve bunları okuyucunun anlayabileceği bir biçimde düzenleyerek yorumlamaktır" (Yıldırım ve Şimşek, 2008, s. 227). Veri analizi sırasında ders kitaplarındaki metinler Orhun Yazıtları ile ilgili sözcükler temel alınarak ve görseller açısından değerlendirilmiştir. İçerik analizinde her bir araştırmacının seçilen kitapları araştırma amacı doğrultusunda ayrı ayrı incelemesiyle güvenirlik sağlanmaya çalışılmıştır.

\section{Bulgular}

Araştırmanın bu bölümünde elde edilen bulgular tablolar hâlinde verilecektir.

Tablo 1. İlkokul Ders Kitaplarında Orhun Yazıtları İle İlgili İçerik

\begin{tabular}{lllll}
\hline Sınıf & Ders Kitabı & Toplam Sayfa & $\begin{array}{l}\text { Orhun Yazıtları İçerikli } \\
\text { Toplam Sayfa }\end{array}$ & $\begin{array}{l}\text { Geçiş } \\
\text { Sıklı̆ı (f) }\end{array}$ \\
\hline 1 & Türkçe & 160 & - & - \\
1 & Hayat Bilgisi & 204 & - & - \\
2 & Türkçe & 317 & - & - \\
2 & Hayat Bilgisi & 246 & - & - \\
3 & Türkçe & 304 & - & - \\
3 & Hayat Bilgisi & 236 & - & - \\
4 & Türkçe & 265 & - & - \\
4 & Sosyal Bilgiler & 208 & - & - \\
\hline TOPLAM & & $\mathbf{1 9 4 0}$ & - & - \\
\hline
\end{tabular}


Tablo 1'e göre sekiz ilkokul ders kitabında toplam 1940 sayfa bulunmaktadır. İncelenen kitaplar içerisinde Orhun Yazıtları ile ilgili herhangi bilgiye rastlanmamıştır. Buna göre Orhun Yazıtları'ndan ilkokul düzeyinde bahsedilmediği anlaşılmaktadır.

Tablo 2. İlkokul Ders Kitaplarında Orhun Yazttları İle İlgili Görseller

\begin{tabular}{lllll}
\hline Sınıf & Ders Kitabi & $\begin{array}{l}\text { Toplam } \\
\text { Görsel }\end{array}$ & Orhun Yazıtları İle İlgili Görsel & $\begin{array}{l}\text { Sayfa } \\
\text { Numarası }\end{array}$ \\
\hline 1 & Türkçe & 356 & - & - \\
1 & Hayat Bilgisi & 560 & - & - \\
2 & Türkçe & 598 & - & - \\
2 & Hayat Bilgisi & 461 & - & - \\
3 & Türkçe & 270 & - & - \\
3 & Hayat Bilgisi & 405 & - & - \\
4 & Türkçe & 170 & - & - \\
4 & Sosyal Bilgiler & 407 & - & - \\
\hline TOPLAM & 3227 & - &
\end{tabular}

Tablo 2'ye göre sekiz ilkokul ders kitabında toplam 3227 görsel bulunmaktadır. İncelenen ders kitapları içerisinde Orhun Yazıtları ile ilgili herhangi bir görsele rastlanmamıştır.

Tablo 3. Ortaokul Ders Kitaplarında Orhun Yazıtları İle İlgili İçerik

\begin{tabular}{lllll}
\hline Sınıf & Ders Kitabı & $\begin{array}{l}\text { Toplam } \\
\text { Sayfa }\end{array}$ & $\begin{array}{l}\text { Orhun Yazıtları } \\
\text { Içerikli Toplam Sayfa }\end{array}$ & $\begin{array}{l}\text { Geçiş } \\
\text { Sılılığ (f) }\end{array}$ \\
\hline 5 & Türkçe & 254 & - & - \\
5 & Sosyal Bilgiler & 205 & - & - \\
6 & Türkçe & 288 & - & - \\
6 & Sosyal Bilgiler & 257 & 7 & 10 \\
7 & Türkçe & 262 & - & - \\
7 & Sosyal Bilgiler & 256 & 3 & 4 \\
8 & Türkçe & 251 & - & - \\
8 & T.C. İnkılap Tarihi ve & 224 & - & - \\
\hline TOPLAM & Atatürkçülük & $\mathbf{1 9 9 7}$ & $\mathbf{1 0}$ & $\mathbf{1 4}$ \\
\hline
\end{tabular}

Tablo 3'e göre sekiz ortaokul ders kitabında toplam 1997 sayfa bulunmaktadır. İncelenen kitaplar içerisinde 6. sınıf Sosyal Bilgiler ders kitabında 7 sayfada $10 \mathrm{kez}$, 7. sinıf Sosyal Bilgiler ders kitabında 3 sayfada 4 kez Orhun Yazıtları ile ilgili içeriğe yer verilmiştir. Buna göre incelenen 
sekiz ders kitabından yalnızca ikisinde Orhun Yazıtları ile ilgili içeriğe çok kısıtlı bir biçimde yer verildiği anlaşılmaktadır.

Tablo 4. Ortaokul Ders Kitaplarında Orhun Yazıtları İle İlgili Görseller

\begin{tabular}{lllll}
\hline \multirow{2}{*}{ Sınıf } & Ders Kitabı & $\begin{array}{l}\text { Toplam } \\
\text { Görsel }\end{array}$ & $\begin{array}{l}\text { Orhun Yazıtları İle } \\
\text { İlgili Görsel }\end{array}$ & $\begin{array}{l}\text { Sayfa } \\
\text { Numarası }\end{array}$ \\
\hline 5 & Türkçe & 356 & - & - \\
5 & Sosyal Bilgiler & 330 & - & - \\
6 & Türkçe & 135 & - & - \\
6 & Sosyal Bilgiler & 333 & 1 & 48 \\
7 & Türkçe & 216 & - & - \\
7 & Sosyal Bilgiler & 402 & 1 & - \\
8 & Türkçe & 186 & - & - \\
8 & T.C. İnkılap Tarihi ve & 188 & - & \\
\hline & Atatürkçülük & $\mathbf{2 1 4 6}$ & $\mathbf{2}$ \\
\hline
\end{tabular}

Tablo 4'e göre sekiz ortaokul ders kitabında toplam 2146 görsel bulunmaktadır. İncelenen kitaplar içerisinde Orhun Yazıtları ile ilgili 6. sınıf Sosyal Bilgiler ders kitabında 1 ve 7. sınıf Sosyal Bilgiler ders kitabında 1 olmak üzere toplamda 2 görsele yer verilmiştir. Buna göre incelenen ders kitaplarında Orhun Yazıtları ile ilgili çok az görsele yer verildiği anlaşılmaktadır. İlgili görseller şu şekildedir:

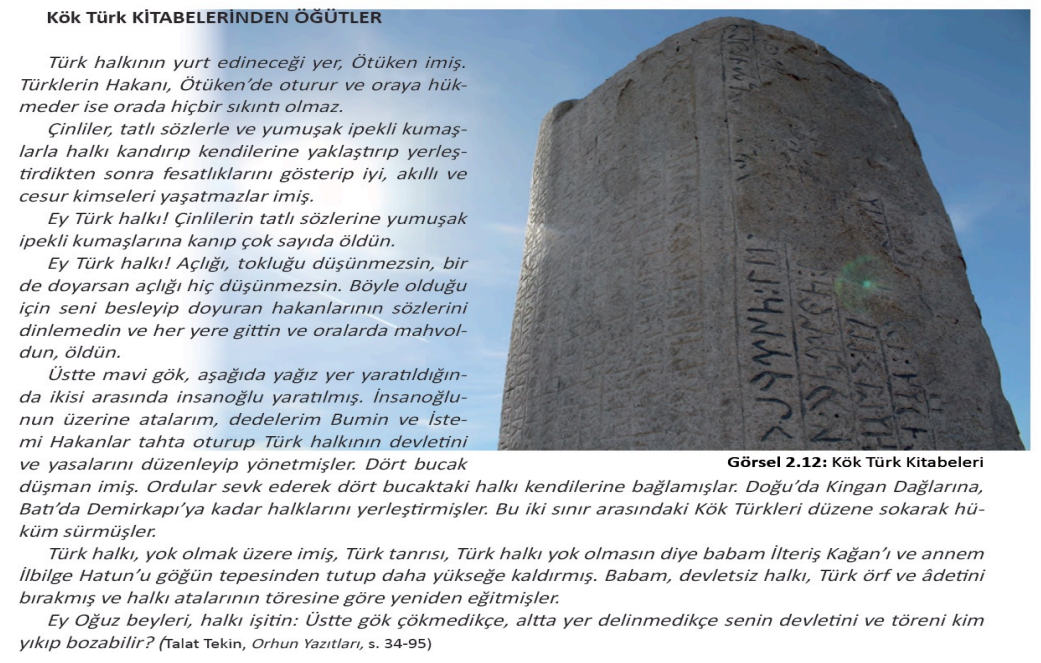

Görsel 1. 6. sınıf Sosyal Bilgiler ders kitabında Bilge Tonyukuk Kitabelerinden birincisine ait görüntü (s. 48) 


\begin{abstract}
Demokraside esas olan insana verilen değer ve gösterilen saygıdır. Demokrasinin göstergelerinden biri de devletin halkın ihtiyaçlarını karşılamasıdır. Tarihimiz boyunca demokratik değerlere ait birçok uygulama görürüz. Köktürklerde insana verilen önemi ve sosyal devlet anlayışını Bilge Kağan Yazıtı'ndaki şu sözler açıkça gösterir:

"Türk milleti için gece uyumadım, gündüz oturmadım. Çıplak milleti giydirdim, fakir milleti zengin ettim. Başka milletlerarasında onları pek üstün kıldım."
\end{abstract}

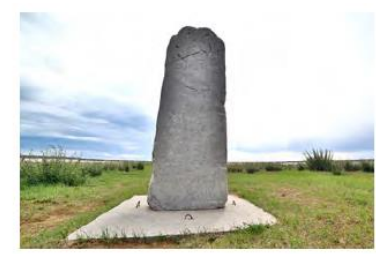

Görsel 6.4: Bilge Kağan Yazıtı

Eski Türk devletlerinde adalet bir devlet töresiydi. Hakan bile kanuna aykırı davranırsa cezalandırılırdı. Türk kültüründe "meşveret" kavramı vardır. Meşveret akıl toplamak demektir. Yani en doğruyu bulmak için birilerine danışılmasıdır. Bu işlem kurultayda yapılırdı. Kurultayda devletin siyasi, askerî ve ekonomik konuları ile ilgili görüşmeler yapılır, kararlar alınırdı. Kurultaya hakanın eşi de katılırdı.

Görsel 2. 7. sınıf Sosyal Bilgiler ders kitabında Bilge Kă̆an Yazıtı'nın kopyasına ait görüntü (s. 199)

Tablo 5. Lise Ders Kitaplarında Orhun Yazıtları İle İlgili İçerik

\begin{tabular}{lllll}
\hline Sınıf & Ders Kitabı & $\begin{array}{l}\text { Toplam } \\
\text { Sayfa }\end{array}$ & $\begin{array}{l}\text { Orhun Yazıtları } \\
\text { Içerikli Toplam Sayfa }\end{array}$ & $\begin{array}{l}\text { Geçiş } \\
\text { Sıklığ (f) }\end{array}$ \\
\hline 9 & Türk Dili ve Edebiyatı & 272 & - & - \\
9 & Tarih & 222 & 4 & 10 \\
10 & Türk Dili ve Edebiyatı & 319 & 7 & 9 \\
10 & Tarih & 207 & - & - \\
11 & Türk Dili ve Edebiyatı & 296 & - & - \\
11 & Tarih & 224 & - & - \\
12 & Türk Dili ve Edebiyatı & 280 & 8 & 11 \\
12 & T.C. İkıllap Tarihi ve & 273 & - & - \\
\hline TOPLAM & Atatürkçülük & $\mathbf{2 0 9 3}$ & $\mathbf{1 9}$ & $\mathbf{3 0}$ \\
\hline
\end{tabular}

Tablo 5'e göre sekiz lise ders kitabında toplam 2093 sayfa bulunmaktadır. İncelenen kitaplar içerisinde 9. sınıf Tarih ders kitabında 4 sayfada 10 kez, 10. sınıf Türk Dili ve Edebiyatı ders kitabında 7 sayfada 9 kez, 13. sınıf Türk Dili ve Edebiyatı ders kitabında 8 sayfada 11 kez Orhun Yazıtlarıyla ilgili içeriğe yer verilmiştir. Buna göre incelenen sekiz ders kitabının üçünde Orhun Yazıtlarının çok kısıtlı bir biçimde ele alındığı anlaşılmaktadır. 
Tablo 6. Lise Ders Kitaplarında Orhun Yazıtları İle İlgili Görseller

\begin{tabular}{lllll}
\hline Sınıf & Ders Kitabı & $\begin{array}{l}\text { Toplam } \\
\text { Görsel }\end{array}$ & $\begin{array}{l}\text { Orhun Yazıtları } \\
\text { Ile İlgili Görsel }\end{array}$ & $\begin{array}{l}\text { Sayfa } \\
\text { Numarası }\end{array}$ \\
\hline 9 & Türk Dili ve Edebiyatı & 145 & - & 17,104 \\
9 & Tarih & 221 & 2 & 21,25 \\
10 & Türk Dili ve Edebiyatı & 154 & 2 & - \\
10 & Tarih & 174 & - & Kapak \\
11 & Türk Dili ve Edebiyatı & 227 & 1 & - \\
11 & Tarih & 181 & - & $20,249,263$ \\
12 & Türk Dili ve Edebiyatı & 187 & 3 & - \\
12 & T.C. İnkılap Tarihi ve & 228 & - & \\
\hline TOPLAM & Atatürkçülük & $\mathbf{1 5 1 7}$ & $\mathbf{8}$ & \\
\hline
\end{tabular}

Tablo 6'ya göre sekiz lise ders kitabında toplam 1517 görsel bulunmaktadır. İncelenen kitaplar içerisinde Orhun Yazıtları ile ilgili 9. sınıf Tarih ders kitabında 2, 10. sınıf Türk Dili ve Edebiyatı ders kitabında 2, 11. sınıf Türk Dili ve Edebiyatı ders kitabında 1 ve 12. sınıf Türk Dili ve Edebiyatı ders kitabında 3 olmak üzere toplamda 8 görsele yer verilmiştir. Buna göre incelenen ders kitaplarında Orhun Yazıtları ile ilgili çok az görsele yer verildiği anlaşılmaktadır. İlgili görseller şu şekildedir:

\begin{tabular}{|l|l|}
\hline Nümizmatik & $\begin{array}{l}\text { Tarih içerisinde basılan paraları inceler (Görsel } \\
1.6) \text {. }\end{array}$ \\
\hline Paleografya & $\begin{array}{l}\text { Yazıları, alfabeleri ve bunların zaman içerisindeki } \\
\text { değişimlerini inceler. }\end{array}$ \\
\hline Filoloji & Dillerin tarihini, gelişimini ve değişimini araştırır. \\
\hline Epigrafi & Kitabeleri inceler. \\
\hline
\end{tabular}

\section{Türklerin İlk Yazılı Belgeleri}

Tarihte "Türk" adının geçtiği yazılı ilk metinler Orhun Kitabeleri'dir (Görsel 1.7). Bu kitabeler hakkında ilk bilgiler XIII. yüzyılda yaşayan Cuveynî́nin "Tarih-i Cihangüşa" isimli eserinde yer alır. Cüveynî, eserinde Uygur bölgesini gezerken rastladığı garip işaretlerle yazılmış taşlardan söz etmektedir. Daha sonra Danimarkalı Messerschmidt'in (Mesırşmit) 1721'de bu eseri görerek Avrupa bilim camiasına tanıtması üzerine birçok bilim adamı bu yazıların kime ait olduğu hakkında tahminlerde bulunmuştur. Bu bilim insanlarının bazıları bu yazıların; Prusyalılara, İskitlere, Yunanlara ve Latinlere ait olduğunu ileri sürmüştür. Bölgeye giden birçok araştırmacı burada kazılar yaparak yeni kalıntılar tespit etmiştir. Kitabelerin okunuşunu ilk çözen Danimarkalı Dil Bilimci W. Thomsen (V. Tomsen) olmuş ve bu abidelerin Türklere ait olduğunu tüm dünyaya duyurmuştur. Orhun Kitabeleri hakkında yapılan bilimsel çalışmaların sonucunda; Türklerin yaşantılarına, töresine, kültürüne ve devlet yönetimine dair bilgiler bulunmuştur (Gömeç, 2000, s.64-65'ten düzenlenmiştir).

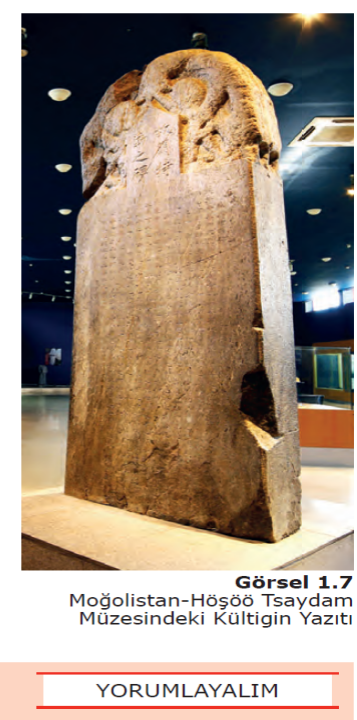

Görsel 3. 9. sını Tarih ders kitabında Köl Tigin Yazıtı'nın batı yüzüne ait görüntü (s. 17) 


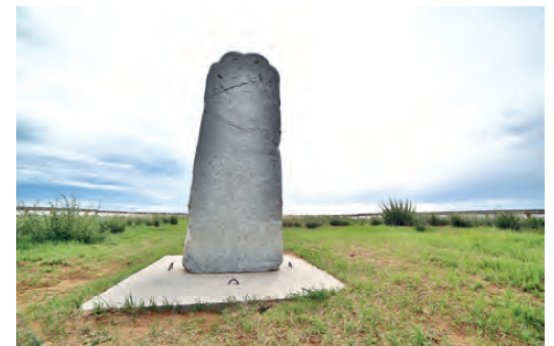

Görsel 4.14

Orhun Yazıtlarından biri (Moğolistan)
Türk kağanları ülkelerinde adaletin sağlanmasına büyük önem vermiştir. Orhun Kitabeleri'nde (Görsel 4.14) töre kelimesinin, on bir yerde geçmesi ve bunun altısının il ile birlikte kullanılmış olması bunun bir göstergesidir. Ayrıca devletin varlığını devam ettirmesi, törelere bağlılık ile ilişkilendirilmiştir. Devlet ile törenin eş değer olduğunu, abidelerdeki şu cümleler açıklamaktadır: "Ey Türk budunu (milleti), devletini, töreni kim bozabilir." Törenin en önemli değeri olan adalet de bu yüzden mülkün yani devletin temeli kabul edilmiştir. Devlet teşkilatlanmasında düzenleyici bir role sahip olan töre, kağanın hem keyfî hareket etmesini engellemiş hem de halkına adil davranması için bir kontrol mekanizması olmuştur.

Görsel 4. 9. sınıf Tarih ders kitabında Bilge Kağan Yazıtı'nın kopyasına ait görüntü (s. 104)

İslamiyet'in Kabulünden Önceki Türk Edebiyatı Ürünlerinden Örnekler

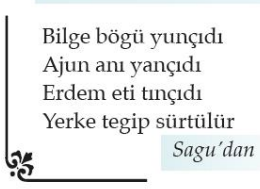

\author{
Yüknüp manga imledi \\ Közüm yaşın yamladı \\ Bağrım bașın emledi \\ Elkin bolup ol keçer \\ Koşuk'tan
}

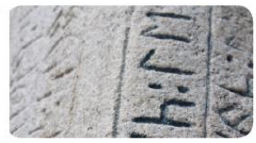

Kök Türk Yazıtları'ndan

Görsel 5. 10. sınıf Türk Dili ve Edebiyatı ders kitabında Bilge Tonyukuk Yazıtı'nın birincisine ait görüntü (s. 21)

\section{TÜRK YAZI DİLİNINN TARİHÎ GELISSMESİ}

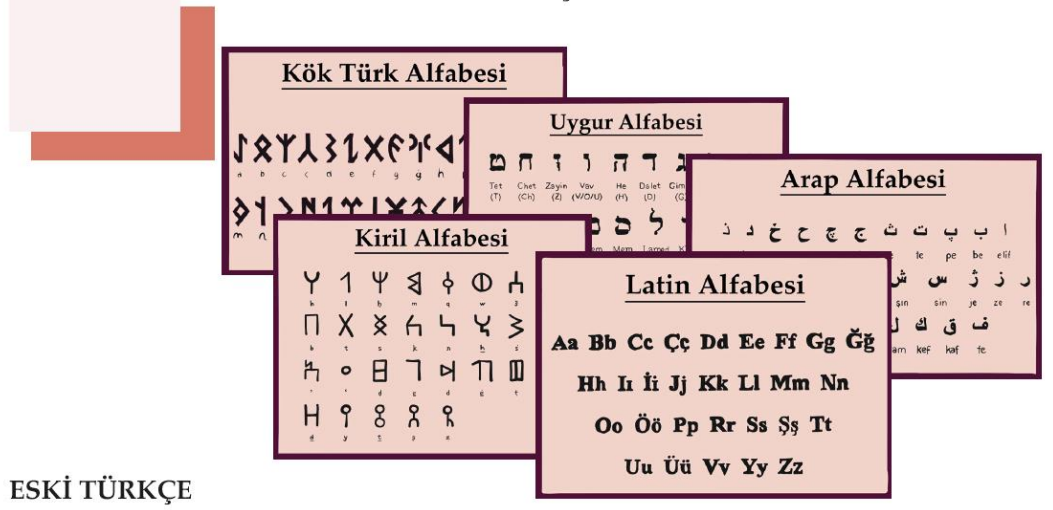

Görsel 6. 10. sınıf Türk Dili ve Edebiyatı ders kitabındaki ilgili görüntü (s. 25). 


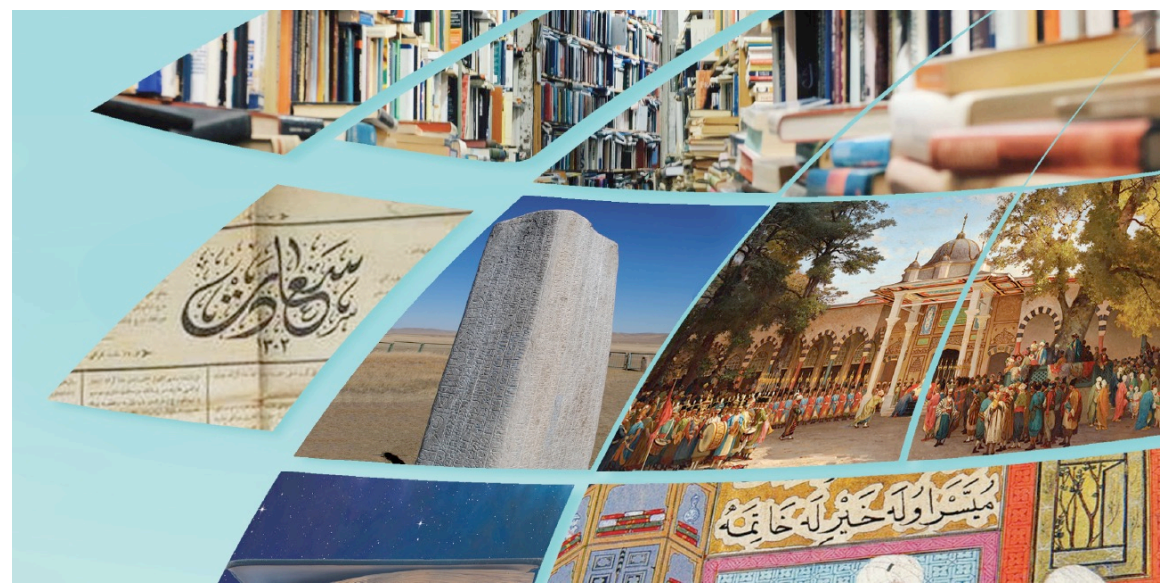

Görsel 7. 11. Sınıf Türk Dili ve Edebiyatı ders kitabının kapağındaki Bilge Tonyukuk Yazıtlarndan birincisine ait görüntü

\section{Metin ve Türle İlgili Açıklamalar}

Dil; temeli bilinmeyen zamanlarda atılmış, kendi doğal yapısı ve kuralları içerisinde yaşayan ve gelişen, canlı bir varlık, sosyal bir kurumdur. Her dilin doğuşu, ortaya çıkışı, gelişimi ve kullanılışı zorlamayla değil, kendi doğal yapısı, işleyişi ve kuralları doğrultusunda gerçekleşir. Bütün doğal diller; her canlı varlık gibi doğar, büyür, gelişir, değişir ve ölür. Bir dildeki değişim o dilin kendi iç ve dış dinamikleri ile gerçekleşir.

Bir dil, kendi kuralları içerisinde ses, söz varlığı ve șekil bakımından zamanla değişebilir. Örneğin; "kel- > gel-", "könül > gönül", "edgü > eygü > eyü > eyi > iyi”... Kimi zaman da bir dildeki bazı kelimeler anlam değişmesine uğrayabilir. Örneğin; "yavuz" kelimesi eski Türkçede "kötü, hırsız" anlamlarına sahipken günümüzde "yiğit, iyi, gürbüz, güzel" anlamlarını karşılar.

Bir dildeki değişim çoğunlukla konuşma dilinde başlayıp daha sonra da yazı dilini etkiler. Çünkü konuşma dilin-

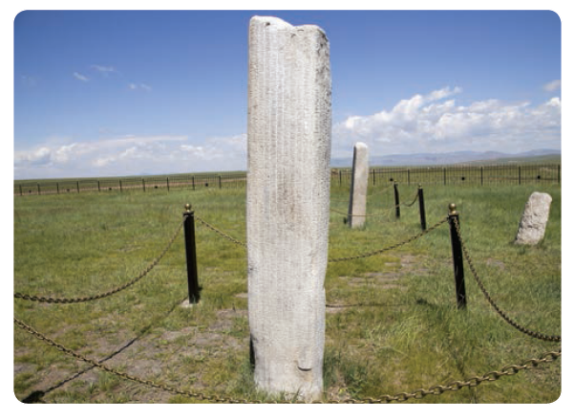

deki değişim yazı diline oranla daha hızıı olur. Yazı dili durağan, konuşma dili ise dinamik olduğu için zamanla yazımla söyleyiş arasındaki fark büyür ve yazı dilinde reform yapma ihtiyacı ortaya çıkar.

Görsel 8. 12. sınıf Türk Dili ve Edebiyatı ders kitabında Bilge Tonyukuk Yazıtlarına ait görüntü (s. 20) 
Osman Mert - Kürşad Çağrı Bozkırlı - Harun Şahin - İlhan Akgün

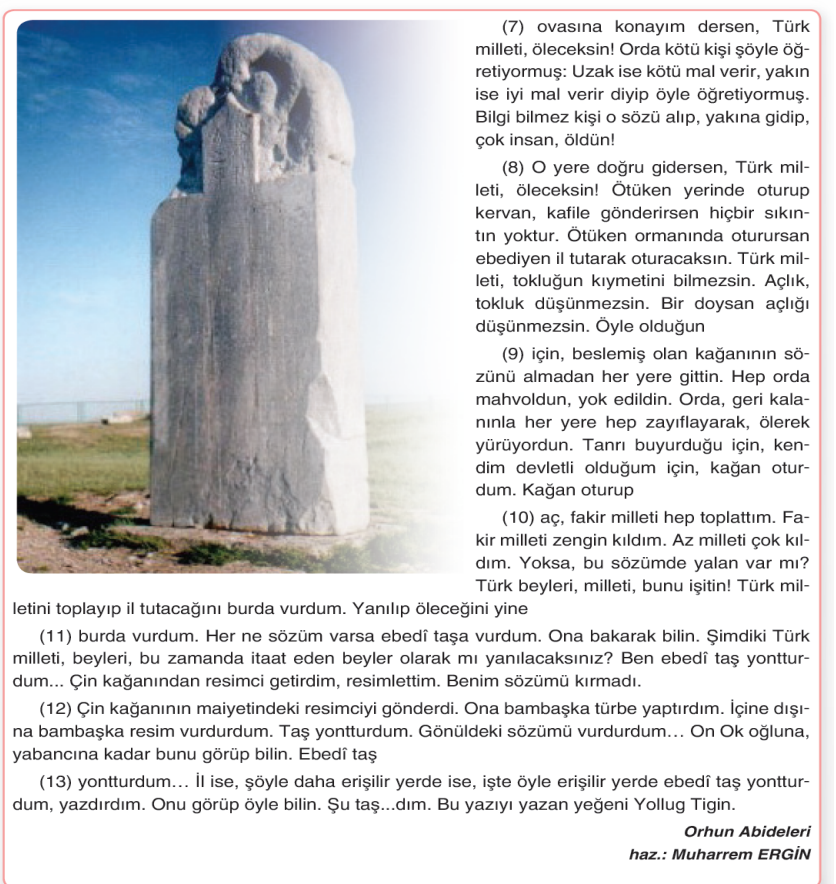

Görsel 9. 12. sınıf Türk Dili ve Edebiyatı ders kitabında Köl Tigin Yazıtı'nın batı yüzüne ait görüntü (s. 249)

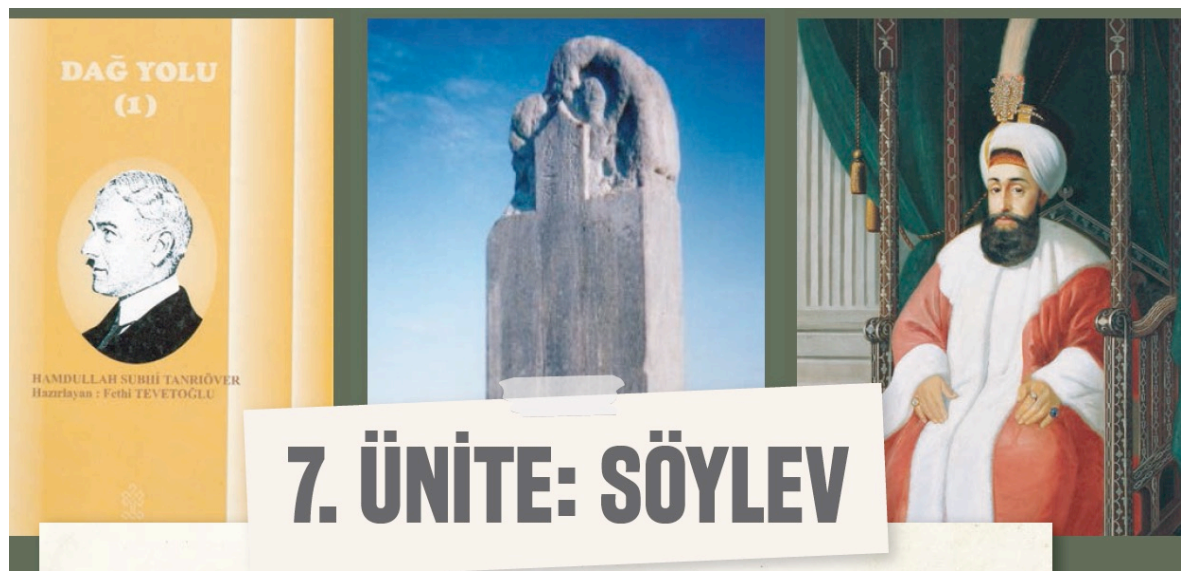

Görsel 10. 12. Sınıf Türk Dili ve Edebiyatı ders kitabında Köl Tigin Yazıtı'nın batı yüzüne ait görüntü (s. 263) 


\section{Sonuç ve Tartışma}

$\mathrm{Bu}$ araştırma ile temel eğitim ders kitaplarında Orhun Yazıtlarının durumu tespit edilmiştir. Araştırma kapsamında ilkokul düzeyinde 8, ortaokul düzeyinde 8 ve lise düzeyinde 8 ders kitabı olmak üzere toplamda 24 ders kitabı Orhun Yazıtlarıyla ilgili içerik ve görsel açısından değerlendirilmiştir. Araştırma sonucunda ilkokul ders kitaplarında Orhun Yazıtlarıyla ilgili herhangi bir içerik ve görsele rastlanmazken, ortaokul düzeyinde iki kitabın (6. ve 7. sınıf Sosyal Bilgiler) 10 sayfasında 14 kez Orhun Yazıtlarıyla ilgili içeriğe yer verildiği, ilgili içeriğin yalnızca iki görselle desteklendiği; lise düzeyinde ise üç kitabın (9. sınıf Tarih, 10. sınıf Türk Dili ve Edebiyatı, 12. sınıf Türk Dili ve Edebiyatı) 19 sayfasında 30 kez Orhun Yazıtlarıla ilgili içeriğe yer verildiği ve ilgili içeriğin sekiz görselle desteklendiği tespit edilmiştir. Kültür aktarımının ve Orhun Yazıtlarının Türk kültürü açısından önemi düşünüldüğünde temel eğitim ders kitaplarının Orhun Yazıtlarıyla ilgili içerik ve görsel açısından oldukça yetersiz olduğu görülmektedir. İlkokulda Orhun Yazttları ile ilgili herhangi bir içerik ya da görsele yer verilmemiş olması oldukça düşündürücüdür. Gürel ve Çetin (2018) sosyal bilgiler dersinin kültür aktarımı açısında oldukça önemli olduğunu belirttikleri araştırmalarında mevcut ders içeriğinin kültürel konulara yer verme açısından yetersiz olduğunu, bu yetersizliğin teknolojinin ve küreselleşmenin kültür üzerinde yarattığ1 yıkımı engellemede okulun gücünü azalttığını vurgulamışlardır. Bu açıdan bakıldığında gerek ilkokul ders kitaplarında Orhun Yazıtlarından hiç bahsedilmemesinin, gerekse ortaokul ve lise ders kitaplarında oldukça sınırlı bir biçimde bahsedilmesinin benzer bir sonuca hizmet edeceği düşünülmektedir.

Ortaokul Türkçe ders kitaplarında Orhun Yazıtlarından hiç bahsedilmemiş olmasının bu dersin doğasına ve varlık sebebine aykırı bir durum olduğu düşünülmektedir. Çünkü Millî Eğitim Bakanlığına (MEB, 2019) göre Türkçe dersinin özel amaçları arasında "millî, manevi, ahlaki, tarihî, kültürel, sosyal değerlere önem vermelerinin sağlanması, millî duygu ve düşüncelerinin güçlendirilmesi" yer almaktadır. Yılar'a (2016) göre de çoğunlukla ders kitapları üzerinden yürütülen Türkçe derslerinde ders kitaplarının değer aktarımı açısından önemli yeri vardır. Bu bakımdan ortaokul Türkçe ders kitaplarının dersin amaçlarına hizmet etmediği açıktır. 
Temel eğitim ders kitaplarının Orhun yazıtlarıyla ilgili mevcut durumu ışığında ders kitaplarının ortak tarih ve gelecek bilinci oluşturabilmesi ve kültür aktarımına katkı sağlayabilmesi adına Orhun Yazıtları ile ilgili içeriğinin yetersiz olduğu ve gözden geçirilmeye ihtiyaç duyduğu değerlendirilmektedir. Zira Kaplankıran'a (2017) göre de ders kitaplarında Köktürk Yazıtları'na yer verilmesi Türk dünyasında ortak kimlik inşası ve kolektif bilincin gelişmesi açısından önemlidir. Yapılacak farklı araştırmaların Türkçenin ve Türk kültürünün temel kaynaklarının ders kitaplarındaki yerinin tespitine ve böylelikle eğitim sistemi ile ilgili daha sağlıklı değerlendirmelere katkı sağlayacağ 1 düşünülmektedir. 


\title{
EXTENDED ABSTRACT
}

\section{The Place of Orkhon Inscriptions in Basic Education Course Books}

\author{
* \\ Osman Mert - Kürşad Çağrı Bozkırlı - Harun Şahin - İlhan Akgün \\ Atatürk University, Kafkas University, Council of Higher Education, National Education Ministry
}

Learning about the culture of the nation in which one is born is actually a process of developing an identity that helps individuals gain a specific (in fact, a nation-specific) perspective of life and become a part of the nation, thinking as "we" instead of "I" (Mora, 2008; Mert, Bay, Alyılmaz and Akbaba, 2010; Alyılmaz and Alyılmaz 2014). This process leaves such longlasting impressions on the person that, for instance, "We prefer living in poverty in our own society while it is possible to have a much more prosperous life in another community. Because this poverty among friends makes us happier than the prosperity among foreigners" (Gökalp, 2015, p. 37). Thus, it can be said that a common culture convenes people around the feelings of happiness and sadness and particularly around the desire for a common future.

Cultures of nations, including their value judgments, beliefs, and traditions, all of which make up their perception of life, are different from each other. Therefore each nation has different expectations from education and from students who are the outputs of this process. In this respect, it is very important for education both to have universal qualities and to be national and "specific".

In spite of all technological developments, course books are still one of the most commonly used educational tools in the world (Yllar, 2016; Doğan and Torun, 2018). Accordingly, the educational tools that play the biggest part in attaining educational goals are course books. Therefore, coursebooks must be qualified enough to serve the educational function of culture transfer.

The orientation of courses is the practical equivalence of idealized views towards the objectives and objectives of educational policies and curricula (Bayram and Elban, 2017). That is, course books can be defined as the mirrors that reflect the actual status of education in the country. In 
that sense, it is believed that the researches on course books shall contribute to identifying the shortcomings and mistakes, if any, generally in the educational system and specifically in course contents and practices. This research is aimed at making a similar contribution to the field, but most importantly, at indicating the place of Orkhon Inscriptions, which is highly significant in terms of Turkish language, history, literature and culture, and has for a long time been considered to be the first written resources of Turks (Aly1lmaz, 2005; Alyılmaz, 2007), in the basic education which is a major and long-lasting part of the Turkish educational system.

\section{Method}

Since the research is based on a review of the basic education course books, it is qualitative research centered on document review. Document review is a research method in which printed and electronic materials are systematically evaluated (Bowen, 2009).

\section{Documents under Review}

The research included a review of Turkish, Life Sciences, Social Sciences, History, Turkish Republic Revolution History, and Kemalism and Turkish Language and Literature course books, which are taught in primary, secondary and high schools in 2018-2019 academic year, in terms of their content and visuals related to Orkhon Inscriptions. The related course books were chosen because they were assumed to include information regarding Orkhon Inscriptions.

\section{Data Analysis}

While the basic education course books were being reviewed as part of the research, the obtained data were analyzed using the content analysis method. "The basic process in content analysis is to gather data that are similar to each other within the framework of specific concepts and themes and to edit and interpret them in a way that a reader can understand" (Yıldırım and Şimşek, 2008, p. 227). During data analysis, the texts in coursebooks were evaluated with respect to the words and the visuals 
related to Orkhon Inscriptions. The reliability of content analysis was ensured by having each one of the researchers review the selected coursebooks separately in line with the purpose of the research.

\section{Conclusion and Discussion}

This study is aimed at determining the place of Orkhon Inscriptions in basic education coursebooks. As part of the research, a total of 24-coursebooks, including 8 at primary, 8 at secondary, and 8 at high school levels were evaluated with regard to their content and visuals related to Orkhon Inscriptions. As the conclusion of the research, it was determined that primary school course books did not have any content or visuals regarding Orkhon Inscriptions, while two books at secondary school level (Social Sciences, $6^{\text {th }}$ and $7^{\text {th }}$ grade) had contents related to Orkhon Inscriptions in 14 places in 10 pages which were supported by only two visuals. Three books at high school level (History, $9^{\text {th }}$ grade, Turkish Language and Literature in $10^{\text {th }}$ grade, Turkish Language and Literature in $12^{\text {th }}$ grade) had contents related to Orkhon Inscriptions in 30 places in 19 pages, which was supported by eight visuals. Considering the importance of culture transfer and Orkhon Inscriptions for Turkish culture, it can be said that basic education course books have obviously inadequate content and visuals related to Orkhon Inscriptions. It is rather disturbing that primary school course books do not have any content or visuals regarding Orkhon Inscriptions. In their research where Gürel and Çetin (2018) stated that the social sciences course is very important in terms of culture transfer, they have emphasized that the current course content is inadequate with regard to cultural topics which makes the school more ineffective in fighting with the destruction that technology and globalization cause on the culture. It is believed, looking at the same perspective, that making no mention of Orkhon Inscriptions in primary school course books and making very limited references in secondary and high school course books will serve a similar purpose.

It is thought that making no mention of Orkhon Inscriptions in secondary school Turkish course books is something that is against nature and reason for being of this course. Because the Ministry of National Education 
(MEB, 2019) has stated that the specific purposes of Turkish lessons include "ensuring that students give importance to national, moral, ethical, historical, cultural and social values and reinforcing their national feelings and beliefs". Yilar (2016) also argues that coursebooks play an important role in value transfer, given that Turkish lessons are mostly taught by using course books. Therefore, it is clear that secondary school Turkish course books do not serve the purposes of the course.

In the light of the current condition of basic education course books regarding Orkhon inscriptions, it is concluded that coursebooks have insufficient content with regard to Orkhon inscriptions for the sake of creating a common history and future awareness and helping the transfer of culture and that such content needs further review. Because Kaplankıran (2017) also emphasizes that making references to Köktürk Inscriptions in coursebooks is important in building a common identity and developing collective conscious in the world of Turks. It is believed that further researches to be made in the future will contribute to finding out the place of the basic resources of Turkish language and culture in course books and thus to making healthier assessments of the education system.

\section{Kaynakça / References}

Alyılmaz, C. (2005). (Kök)türk harfli yazıtların izinde. Ankara: Karam.

Alyılmaz, C. (2007). Orhun Yazıtlarımın bugünkü durumu. Ankara: Kurmay.

Alyılmaz, C. ve Alyılmaz, S. (2014). Amirbek Turatoviç Muratov'dan Yenisey'e sesleniş. Uluslararası Türkçe Edebiyat Kültür Eğitim Dergisi. 3(1), 68-84.

Arseven, A., Yolcu, F. ve Kılıç, A. Ş. (2018). Ortaokul 6, 7 ve 8. sinıf Türkçe ders kitaplarındaki metinlerin değer eğitimi açısından incelenmesi. Karadeniz Araştırmaları, 15(58), 205-222.

Barutçu, T. ve Açı, F. (2018). Çocuk edebiyatı ürünlerinde yer alan deyimlerin kültür aktarımındaki rolü ve Türkçe ders kitaplarındaki deyimlerle örtüşme düzeyi. bilig, 86, 183-209.

Bayram, B. ve Elban, M. (2017). Türkçe ders kitaplarında milli kimliğe ilişkin unsurların incelenmesi. Akdeniz Eğitim Araştırmaları Dergisi, 21, 19-27.

Bowen, G. A. (2009). Document analysis as a qualitative research method. Qualitative Research Journal, 9(2), 27-40. 
Doğan, Y. ve Torun, F. (2018). Sosyal bilgiler ders kitapları nereye doğru gidiyor? JILSES, 4(2), 111-125.

Ecerkale, N. ve Bayrak, Ö. (2018). Türkçe 7. sınıf ders kitabındaki metinlerin değerler bağlamında incelenmesi. JILSES, 4(2), 277-287.

Er, O. ve Bozkırlı, K. Ç. (2018). Türkçe öğretmeni adaylarının eski Türk eserlerine yönelik tutumlarının çeşitli değişkenlere göre incelenmesi: Kafkas Üniversitesi örneği. I. Multidisipliner Akademik Çalışmalar Sempozyumu Tam Metin Bildiriler Kitabı. 135-144.

Gökalp, Z. (2015). Türkçülü̈̆̈̈n esasları. (haz. S. Çobanoğlu). (2. Baskı). Ankara: Ötüken.

Gürel ve Çetin, T. (2018). Sosyal bilgiler dersi ve kültür aktarımında edindiği rol üzerine bir inceleme. Anadolu Eğitim Liderliği ve Öğretim Dergisi, $6(2), 22-40$.

Kaplankıran, İ. (2017). Kazakistan'daki ortaokul ana dili ders kitaplarında yer alan Köktürkçe unsurlar. Uluslararası Türkçe Edebiyat Kültür Eğitim Dergisi, 6(1), 406-438.

Kaşkaya, A. ve Duran, T. (2017). İlkokul Türkçe ders kitaplarının değer aktarımı açısından incelenmesi. Trakya Üniversitesi Ĕ̈̆itim Fakültesi Dergisi, $7(2), 417-441$.

Kavcar, C. (1999). Edebiyat ve eğitim. (3. Bsm). Ankara: Engin.

Kolaç, E. (2010). Hacı Bektaş Veli, Mevlana ve Yunus felsefesiyle Türkçe derslerinde değerler ve hoşgörü eğitimi. Türk Kültürü ve Hacı Bektaş Veli Araştırma Dergisi, 55, 193-208.

MEB (2019). Türkçe dersi öğretim programı (ilkokul ve ortaokul 1, 2, 3, 4, 5, 6, 7 ve 8. simflar). Ankara: MEB.

MEB. (2018). 1. sinıf hayat bilgisi ders kitabı. Ankara: Kök-E.

MEB. (2018). 1. sinıf türkçe ders kitab.l Ankara: Kök-E.

MEB. (2018). 10. sinıf tarih ders kitabı. Ankara: İlke.

MEB. (2018). 10. sınıf Türk dili ve edebiyatı ders kitabı. Ankara: MEB.

MEB. (2018). 11. sinif tarih der s kitabl. Ankara: MEB.

MEB. (2018). 11. sinıf Türk dili ve edebiyatı ders kitabı. Ankara: Ekoyay.

MEB. (2018). 12. sinıf türk dili ve edebiyatı ders kitabı. Ankara: Tuna.

MEB. (2018). 12. sinıf Türkiye Cumhuriyeti inkılap tarihi ve Atatürkçülük Ders Kitabı. Ankara: MEB.

MEB. (2018). 2. sinıf hayat bilgisi ders kitabı. Ankara: SDR Dikey.

MEB. (2018). 2. sinıf Türkçe ders kitabı. Ankara: Koza.

MEB. (2018). 3. sınıf hayat bilgisi ders kitabı. Ankara: Evrensel İletişim. 
MEB. (2018). 3. sınıf Türkçe ders kitabı. Ankara: SDR Dikey.

MEB. (2018). 4. simı sosyal bilgiler ders kitabı .Ankara: Tuna.

MEB. (2018). 4. sınıf Türkçe ders kitabı. Ankara: MEB.

MEB. (2018). 5. sinif sosyal bilgiler ders kitabı. Ankara: Anadol.

MEB. (2018). 5. sinıf Türkçe ders kitabı. Ankara: MEB.

MEB. (2018). 6. sinıf sosyal bilgiler ders kitabı. Ankara: MEB.

MEB. (2018). 6. sınıf Türkçe ders kitabı. Ankara: Eksen.

MEB. (2018). 7. sinuf sosyal bilgiler ders kitabı. Ankara: MEB.

MEB. (2018). 7. sınıf Türkçe ders kitabı. Ankara: Tuna.

MEB. (2018). 8. sinıf T.C. inkılap tarihi ve Atatürkçülük ders kitabı. Ankara: Top.

MEB. (2018). 8. sinıf Türkçe ders kitabı. Ankara: MEB.

MEB. (2018). 9. sinıf tarih ders kitabı. Ankara: MEB.

MEB. (2018). 9. sınıf Türk dili ve edebiyatı ders kitabı. Ankara: Sonuç.

Mert, O., Bay, E., Alyılmaz, S. ve Akbaba, S. (2010). Öğretmen adaylarının eski Türk eserlerine ilişkin farkındalık ve tutum düzeylerinin incelenmesi. 8. Uluslararası Türk Dünyası Sosyal Bilimler Kongresi Bildiri Kitabı. 203-214.

Mert, O., Alyılmaz, S., Bay, E. ve Akbaba, S. (2009). Orhun Yazıtlarındaki toplumsal değerlerin öğretmen adayları tarafından algılanma düzeyi üzerine bir inceleme. Uluslararası Sosyal Araştırmalar Dergisi, 2(9), 279287.

Mora, N. (2008). Medya ve kültürel kimlik. Uluslararası İnsan Bilimleri Dergisi, 5(1), 1-14.

Pehlivan, A. ve Kolaç, E. (2016). Açık - örgün eğitim sosyal bilgiler ders kitapları ve öğretim programında somut olmayan kültürel miras ögeleri. Turkish Studies, 11(19), 655-670.

San, İ. (1988). Kültür aktarımı ve çağdaş kültür sorunu içinde sanat eğitiminin yeri. Ankara Üniversitesi Eğitim Bilimleri Fakültesi Dergisi, 16(2), 137145.

Şahin, N. (2019). Türk dili ve edebiyatı öğretmeni adaylarının karakter ve eğerler eğitimi dersine yönelik görüşlerinin incelenmesi. OPUS-Uluslararası Toplum Araştırmaları Dergisi, 11(18), 1058-1090. DOI: 10.26466/opus.569630

Ünveren-Kapanadze, D. (2018). Dil ve kültür aktarımında işlevsel bir araç olarak ders kitapları: Türkçe ders kitapları örneği. Turkish Studies, 13(27), 1575-1592. 
Yılar, R. (2016). İlettiği değerler açısından ilkokul Türkçe ders kitaplarındaki metinler üzerinde incelemeler. Bayburt Eğitim Fakültesi Dergisi, 11(2), 490-506.

Yıldırım, A. ve Şimşek, H. (2008). Sosyal bilimlerde nitel araştırma yöntemleri. Ankara: Seçkin.

\section{Kaynakça Bilgisi / Citation Information}

Mert, O., Bozkırlı, K. Ç., Şahin, H. ve Akgün, İ. (2019). Temel eğitim ders kitaplarında Orhun Yazıtlarının durumu. OPUS-Uluslararası Toplum Araştırmaları Dergisi, 14(20), 551-571. DOI: 10.26466/ opus.602977 